\title{
La modificación de los modos de gestión de servicios públicos, en el Proyecto de Ley de régimen jurídico del sector público
}

\author{
Javier Bermúdez Sánchez \\ Profesor de derecho Administrativo. Universidad Autónoma de Madrid \\ javier.bermudez@uam.es
}

\section{PLANTEAMIENTO}

Como se va a detallar, el legislador, en el art. 86 de este Proyecto Proyecto de Ley de régimen jurídico del sector público -LRJSP, parece tener como objetivo regular una cuestión técnica, esto es, los denominados "medios propios y servicio técnico" a los efectos de evitar que a la gestión de servicios públicos por organismos o entidades públicas o privadas de la Administración, se aplique la legislación de contratos del sector público y su interpretación por la justicia de la Unión Europea, y ello con amparo en el principio de racionalización en el gasto público en época de crisis. Este precepto, incluye una determinación que supone, sin embargo, algo de más profundo calado, de fuerte y predominante componente político', y lo que es más relevante en el contexto jurídico de estas jornadas, pues en realidad es una propuesta huérfana a mi juicio de encaje legal y constitucional, o, cuando menos, muy discutible, como es la preferencia por la gestión indirecta de los servicios públicos frente a la directa por entidad del sector público institucional del Estado, que invierte la mucho más razonable regla existente hasta la fecha, y que bajo el mismo principio constitucional de racionalización del gasto público² suponía que la contratación deberá considerarse sólo en casos de insuficiencia de medios propios en la Administración. Así, la preferencia actual en esta opción se determina, entre otros, en el artículo 22 del actual Texto Refundido de la Ley de contratos del sector público, que, si bien está referido a la justificación de la necesidad del fin, se presupone en el mismo la necesidad de justificar para contratar, esto es, la insuficiencia de medios en la Administración pública³.

Sin duda, una finalidad legítima del legislador en este contexto de crisis y en todo caso de racionalidad del gasto, hubiera sido la de controlar que las Administraciones públicas no creen "artificialmente" (de forma irracional o irresponsable o, en definitiva, arbitrariamente) entidades cuyos gastos no resulten plenamente justificados, bajo la óptica de la eficiencia y eficacia, esto es, mejor servicio con coste racional o soportable (pensemos en casos reales de entidades en las que ha habido efectivamente cierto dispendio, inaceptable para el presupuesto público),

$1 \quad$ Véase al respecto la llamativa referencia que en el segundo párrafo de la exposición de motivos de este Proyecto LRJSP se hace al informe de la CORA, en concreto al papel de las Administraciones al servicio de los ciudadanos y las empresas:

"El informe, que fue elevado al Consejo de Ministros el 21 de junio de 2013, formuló 218 propuestas basadas en el convencimiento de que una economía competitiva exige unas Administraciones Públicas eficientes, transparentes, ágiles y centradas en el servicio a los ciudadanos y las empresas."

2 De acuerdo con el citado principio del artículo 31. 2 Const., se atenderá a los criterios de eficiencia y economía en el gasto público.

3 Como ejemplo, esta insuficiencia de medios en la Administración es aplicada expresamente en la Sentencia del Tribunal Superior de Justicia de Cataluña 9 mayo 2012, recurso n 462/2009, ponente HORCAJADA MOYA. La sentencia conoce del recurso contra la convocatoria de licitación por procedimiento abierto de un contrato de gestión de servicios públicos consistente en el desarrollo de programas de medidas penales alternativas, del Departamento de Justicia de Cataluña. La sentencia, respecto a esta cuestión resuelve:

"QUINTO.- Alega también la actora que la Administración no ha acreditado en el expediente de contratación la insuficiencia de medios personales y materiales de que dispone para realizar otros servicios, según exige el art. 22 de la Ley de contratos del sector público. Sin embargo, el informe justificativo al efecto (documento $n^{\circ} 1$ del expediente) asevera que: el Departament de Justícia no disposa de mitjans personals ni materials propis per dur a terme la prestació d'aquest servei públic d'acord amb les exigències actuals (els darrers anys s'ha donat un creixement exponencial de les demandes d'execució de mesures penals alternatives, que l'any 2008 ha supusat un increment interanual del $110 \%$ ). Per tal de garantir a la societat catalana que allò que determinen els òrgans judicials es compleix de manera adequada i dins d'uns terminis sostenibles, ha estat necessària una revisió del model de gestió del Programa d'MPA. D'acord amb la descripció que es fa al plec de condicions tècniques el nou model de gestió exigeix la contractació d'entitats externes que collaborin en la gestió de les mesures penals alternatives". Pero es que, con independencia de lo anterior, la representación letrada de la demandada, en su escrito de contestación a la demanda, expone detalladamente el conjunto de tareas que atienden los alrededor de 200 profesionales del Departament en relación al ámbito territorial de Cataluña, que hace imposible añadir la carga de trabajo que supone la atención de más de 16.000 peticiones anuales de MPA.”De su exposición puede deducirse sin la menor duda la insuficiencia de medios personales del Departament para el desarrollo de estos TBC y MPA. Exposición que no es rebatida con alegatos o pruebas por parte de la recurrente". 
pero ese fin ya está por ejemplo en el mismo Proyecto, en su art. 85, referido al control de eficacia y supervisión de las “entidades del sector público institucional”. Efectivamente hay que impedir cualquier derroche y malversación en las Administraciones públicas, pero para ello la medida a adoptar deberá ser la de mejorar los controles, hasta ahora claramente insuficientes, sin olvidar el contexto en el que gran parte de este dispendio se produce, en el recurso de las Administraciones al Derecho privado, en el que los controles y garantías son consustancialmente menores. Pero no es eso lo que preceptúa el artículo comentado ¿Qué se regula entonces en el art. 86 de este Proyecto LRJSP?

\section{LA REDACCIÓN DEL ART. 86 PROYECTO LRJSP Y SU ANTECEDENTE EN EL ANTEPROYECTO}

El artículo 86 del Proyecto LRJSP tiene por objeto la regulación de lo que deba considerarse "medio propio y servicio técnico", en consideración a la legislación y jurisprudencia europea sobre contratos, teniendo en cuenta la necesidad de que la entidad tenga atribuida expresamente la condición de "medio propio y servicio técnico" del mismo, de acuerdo con lo estipulado hoy en el artículo $4.1 \mathrm{n}$ ) del Real Decreto legislativo 3/2011, de 14 de noviembre, por el que se aprueba el Texto Refundido de la Ley de Contratos del Sector Público ${ }^{4}$.

Con ese objetivo y en ese marco de la legislación de contratos, estipula el apartado primero del artículo 86 del Proyecto:

4 Sobre esta exigencia véase en la doctrina, con Alfonso SANTAMARÍA PASTOR, Principios de Derecho administrativo general, volumen II, página 327; y asimismo en la jurisprudencia, la doctrina del Tribunal de Justicia de las Comunidades Europeas, en su aplicación interna, en la Sentencia del Tribunal Supremo de 25 enero 2013, recurso de casación 3351/2010, ponente CALVO ROJAS, sobre una sociedad anónima aragonesa, en la que se aplica la jurisprudencia enunciada como “criterios Teckal”, esto es, que la Administración pública ejerza control análogo al que ejerce sobre sus propios servicios, y que la entidad realice la parte esencial de su actividad con el ente o entes que la controlan. La sentencia, muy relevante al respecto, resuelve el recurso de casación de la compañía Chiné, Almacenaje y Distribución S. L. contra el acuerdo del Gobierno de Aragón de 13 de diciembre de 2005 por el que se aprueba el Proyecto Supramunicipal de la Plataforma Logístico Industrial y Centro del Transporte de Fraga (Huesca). En ese proyecto de alcance supramunicipal se establece la atribución de la gestión de la actuación a la sociedad "Suelo y Vivienda de Aragón SLU”, designándola igualmente como beneficiaria de la expropiación. La sentencia resuelve que se trata de una encomienda de gestión o un encargo de ejecución de la Administración autonómica a uno de sus medios instrumentales: una empresa dependiente y subordinada, creada precisamente para atender determinados tipos de desarrollos de suelo, y que tiene condición de medio propio instrumental de la Administración. Y ello con base en la jurisprudencia europea y española en los términos siguientes:

“TERCERO.- Entrando entonces a examinar el único motivo de casación, hemos visto que la recurrente alega la infracción del artículo 86 del Tratado Constitutivo de la Comunidad Europea y de la doctrina del Tribunal de Justicia de la Unión Europea, aduciendo que la decisión de otorgar -mediante la asignación dela condición de beneficiaria de la expropiación- un derecho exclusivo de gestión urbanística a favor de una sociedad dependiente de la Administración, sin que haya mediado concurrencia, es contraria a lo dispuesto en los artículos 86,43 y 49 del Tratado Constitutivo de la Comunidad y, por lo tanto, contraria a derecho. Frente a ello se argumenta en los escritos de oposición de las partes recurridas que el caso examinado constituye un expediente de contratación doméstica, la denominada “ in house providing”; tesis ésta que compartimos, lo que nos llevará a desestimar el motivo de casación. Veamos. "El artículo 86 del Tratado de la Unión Europea dispone ...”El Tribunal de Justicia de la Unión ha elaborado un sostenido cuerpo de doctrina en torno a la aplicaciónde esa previsión a los supuestos de encomienda a un ente que tiene la condición de medio propio de la Administración..." De acuerdo con esa doctrina, para decidir si se está en presencia de un contrato doméstico o "in house",o, dicho de otro modo, para determinar si la empresa que ha de realizar la actividad o prestación merece la condición de medio propio de la Administración y, por tanto, puede acordarse la adjudicación directamente a esa empresa dependiente sin acudir a los procedimientos competitivos y sin vulnerar el sistema de libre concurrencia, la jurisprudencia comunitaria ha venido exigiendo la concurrencia de dos condiciones, que se conocen como “criterios Teckal”. Esas condiciones son: $1^{\circ}$ ) Que la Administración pública ejerza sobre el ente de que se trate un control análogo al que ejerce sobre los propios servicios; $\mathrm{y}^{\circ}$ ) Que la entidad realice la parte esencial de su actividad con el ente o los entes que la controlan. "Solo si se dan conjuntamente tales condiciones el ente de que se trate podrá ser considerado entidad"in house" con respecto al organismo adjudicador a efectos de que se le puedan confiar tareas sin pasar por un procedimiento de adjudicación en competencia. Y precisamente por la exigencia de las dos condiciones a que acabamos de referirnos la jurisprudencia no ha considerado sociedades "in house" a entidades privadas con participación de capital del poder adjudicador, al entender que la Administración no ejercía sobre la sociedad participada un control análogo al que ejerce sobre sus propios servicios (Asunto Roane).”Especialmente significativa es la sentencia del Asunto Tragsa (STJCE 19 de abril de 2007) que resolvió la cuestión prejudicial planteada por este Tribunal Supremo..."Como consecuencia de la resolución de la cuestión prejudicial, la sentencia de este Tribunal Supremo de19 de abril de 2007 (casación $548 / 2002$ ) declaró la inaplicación a la sociedad pública Tragsa de la Legislación de Contratos de las Administraciones Públicas y de las directivas comunitarias sobre contratación pública. "Esa doctrina ha encontrado reflejo en nuestra legislación interna sobre contratación pública, en concreto en los artículos 4.1.n y 24.6 de la Ley 30/2007 de Contratos del Sector Público, aunque tales preceptos no resulten aplicable por razones temporales pues aquí resulta de aplicación el texto refundido de la Ley de Contratos de las Administraciones Públicas aprobado por Real Decreto Legislativo 2/2000."'La Directiva 2004/18, sobre coordinación de los procedimientos de adjudicación de los contratos públicos de obras, de suministro y de servicios, que rige en la materia, "no contiene ninguna disposición comparable al art. 6 de la Directiva 92/50 , que excluye de su ámbito de aplicación los contratos públicos adjudicados, en determinadas condiciones, a entidades adjudicadoras" (STJCE de 18 de enero de 2007 , C220/05, Jean Auroux y otros, apartado 60). Con todo, esta doctrina es aplicable a las tres Directivas de sectores clásicos (obras, suministros y servicios), hoy refundidas en la Directiva 2004/18, ya que “... el Tribunal de Justicia ha confirmado la aplicabilidad de las mismas consideraciones a las Directivas 92/50, relativa a los contratos públicos de servicios, y 93/37/CEE del Consejo, de 14 de junio de 1993 , sobre coordinación de los procedimientos de adjudicación de los contratos públicos de obras" (STJCE de 13 de octubre de 2005, C458/03, Parking Brixen, apartado 59). Y aun cabe añadir que la STJCE de 13 de enero de 2005 (C-84/03, Comisión/España), consideró contraria a la doctrina Teckal y, por tanto, a las Directivas de suministro y obras, la exclusión a priori y absoluta del ámbito de aplicación del Texto Refundido de la Ley de Contratos de las Administraciones Públicas de los convenios de colaboración que celebren las Administraciones Públicas con las demás entidades públicas, sea cual sea la naturaleza de estas relaciones, y, por tanto, también los convenios que constituyan contratos públicos a efectos de dichas Directivas (apartados 40 y 41)." 
“Las entidades integrantes del sector público institucional podrán ser consideradas medios propios y servicios técnicos de los poderes adjudicadores y del resto de entes y sociedades que no tengan la consideración de poder adjudicador cuando cumplan las condiciones y requisitos establecidos en el Texto Refundido de la Ley de Contratos del Sector Público, aprobado por el Real Decreto Legislativo 3/2011, de 14 de noviembre."

A su vez, el párrafo segundo del artículo 86 del Proyecto estipula:

“2. Tendrán la consideración de medio propio y servicio técnico cuando se acredite que, además de disponer de medios suficientes e idóneos para realizar prestaciones en el sector de actividad que se corresponda con su objeto social, de acuerdo con su norma o acuerdo de creación, se dé alguna de las circunstancias siguientes:

a) Es una opción más eficiente que la contratación pública y resulta sostenible y eficaz, aplicando criterios de rentabilidad económica.

b) Resulta necesario por razones de seguridad pública o de urgencia en la necesidad de disponer de los bienes o servicios suministrados por el medio propio o servicio técnico.

Formará parte del control de eficacia de los medios propios y servicios técnicos la comprobación de la concurrencia de los mencionados requisitos.

En la denominación de las entidades integrantes del sector público institucional que tengan la condición de medio propio deberá figurar necesariamente la indicación «Medio Propio» o su abreviatura «M. P.»."

Este apartado plantea diversos problemas de redacción y subsiguientes de interpretación, y en este sentido como elemento previo para su exposición, resulta relevante su contraste con la versión que de la misma materia estipulaba el artículo 61 del Anteproyecto LRJSP:

“2. Sólo podrá crearse un medio propio y servicio técnico cuando se acredite que, además de disponer de medios suficientes e idóneos para realizar prestaciones en el sector de actividad que se corresponda con su objeto social, de acuerdo con su norma o acuerdo de creación, se dé alguna de las circunstancias siguientes:

a) Es una opción más eficiente que la contratación pública y resulta sostenible y eficaz, aplicando criterios de rentabilidad económica.

b) Resulta necesario por razones de seguridad pública o de urgencia en la necesidad de disponer de los bienes o servicios suministrados por el medio propio o servicio técnico.

Formará parte del control de eficacia de los medios propios y servicios técnicos la comprobación de la concurrencia de los mencionados requisitos.

En la denominación de las entidades que tengan la condición de medio propio deberá figurar necesariamente la indicación «Medio Propio» o su abreviatura «M.P.».

Un organismo público no tendrá que cumplir los requisitos establecidos en las letras a) y b) anteriores ni incluir en su denominación la indicación de «Medio Propio» o su abreviatura «M.P.», cuando su actividad como medio propio sea residual respecto de la atribuida en su norma de creación." 
Esta regulación en cualquier caso, y sin perjuicio de los detalles sobre su interpretación, pretende imponer alguna preferencia en la gestión de servicios públicos, en la selección de los modos de gestión de servicios públicos, en concreto en la preferencia de la indirecta sobre la directa mediante sector institucional, y ello al exigir que la prestación de la actividad como medio propio y servicio técnico por una entidad integrante del sector público institucional, sea "más eficiente que la contratación pública y resulta sostenible y eficaz, aplicando criterios de rentabilidad económica".

Esta determinación, se enmarcará en el objetivo de la racionalización y sostenibilidad del servicio público en atención a la actual crisis económica5 , pero incluye una regulación cuyas consecuencias van mucho más allá.

Existen dos modificaciones relevantes en la redacción del precepto en esas dos versiones: en primer lugar, que en el artículo 61. 2 del Anteproyecto se refiere a la "creación" del medio propio o servicio técnico, lo que se silencia en el artículo 86. 2 del Proyecto LRJSP, por lo que se desconoce si se aplica sobre nuevas entidades o también a las ya existentes (¿Deberá dejar de prestar la Entidad Puertos del Estado o las Autoridades Portuarias, servicios que puedan ser más rentables económicamente por contratistas o en su caso de forma previa a cada prestación justificar en un estudio su mejor rentabilidad económica?); y en segundo lugar que el artículo 61. 2, en su párrafo final, se excluía o matizaba la aplicación de estos requisitos de los apartados a) y b) y de la exigencia de que conste expresamente en la denominación de la entidad "medio propio y servicio técnico", para los organismos públicos cuando su actividad como medio propio fuera residual respecto de la atribuida en su norma de creación.

\section{PRECEDENTES EN EL ÁMBITO LOCAL, ART. 85.2 LRBRL, DESDE 2013}

Efectivamente, como me apunta un colega de la Universidad de Valencia el mismo día de la jornada en el INAP, esta regulación tiene un precedente en la redacción actual del artículo 85. 2 de la Ley reguladora de las bases de régimen local, tras su modificación por la Ley 27/2013, de 27 de diciembre, al incluir el principio general de que "Los servicios públicos de competencia local habrán de gestionarse de la forma más sostenible y eficiente de entre las enumeradas a continuación", y además, la preferencia en la gestión directa por la propia entidad local o por organismo autónomo, frente a entidad pública empresarial local o sociedad mercantil local ${ }^{6}$. Esta regulación local, contribuye a mejorar y a articular el principio de eficiencia en el gasto público en el marco de las formas de gestión de los servicios públicos locales, aunque los márgenes de interpretación de este concepto (que incorpora su eficacia o la atención y calidad a los servicios prestados), y su diferenciación del mismo principio en el ámbito económico, meramente de rentabilidad económica ${ }^{7}$, debería haber derivado en una regulación más precisa, lo que me permite cuestionar a priori su posible aplicación por las Administraciones, y aún más en el ámbito local.

\section{NOVEDADES DEL ART. 86.2 PROYECTO LRJSP}

La regulación que se propone en el art. 86. 2 de este Proyecto LRJSP, difiere de ese precedente de la legislación local, porque lo eleva a principio o dogma, más político que jurídico, como se expone a continuación.

En primer lugar, su ámbito subjetivo de aplicación está referido a todas las entidades del sector público institucional del Estado ${ }^{8}$, y además supone en concreto un criterio, en concreto respecto a la preferencia entre la gestión directa (por entidad del sector público distinta de la Administración) o indirecta , que, como se verá, resulta la beneficiada.

En segundo lugar, el art. 86.2 Proyecto LRJSP contiene una regla que está formulada de forma específica y terminante, y no como un mero principio general como es la premisa incluida en el artículo 85. 2 LRBRL ("gestión de la forma más sostenible y eficiente de entre las enumeradas"), pues este art. 86.2 Proyecto LRJSP requiere expresamente la eficiencia en la entidad del sector público estatal, respecto a la contratación púbica, y que sea sostenible y eficaz, "aplicando criterios de rentabilidad económica".

5 En este sentido, L. MORELL OCAÑA, “La organización y las formas de gestión de los servicios en los últimos cincuenta años", en Revista de Administración Pública $n^{\circ}$ 150, 1999, páginas 379 y siguientes ya había hecho referencia en la doctrina a cómo la gestión de los servicios públicos atiende a factores coyunturales como las limitaciones presupuestarias en situaciones de crisis, en concreto páginas 402 y 403.

6 La doctrina deduce de este precepto la preferencia por la gestión indiferenciada. Véanse en este sentido José Luis RIVERO YSERN, Manual de Derecho local, 2014, página 488; y, COSCULLELA, Manual de Derecho administrativo, 2014, página 602.

7 Véase en la doctrina Marcos VAQUER CABALLERÍA, "El criterio de la eficiencia en el derecho administrativo", en la Revista de Administración Pública número 186, 2011, páginas 91 y siguientes, donde refiere cómo la eficiencia es un criterio complementario de la eficacia pero que la presupone o concurre con ella, siendo la eficiencia, modal, que preside la relación óptima entre medios y fines, y la eficacia, final, y aquella sólo cabe en el marco de la justicia e igualdad como valores superiores del ordenamiento jurídico del artículo 1 de la Constitución, que obliga a una debida ponderación entre principios, sin que sea admisible la confusión entre fines y medios que es lo que ocurre, en el ejemplo que cita, en el procedimiento administrativo, (pero que resulta muy ilustrativo a estos efectos) "cuando se eleva a la categoría de objetivos axiomáticos la simplificación y la reducción de cargas administrativas".

8 Evidentemente no tiene carácter básico, como precisa la disposición final cuarta, 2, c) del mismo Proyecto LRJSP. 
Esta previsión incluye un claro y parece que exclusivo o al menos preferente o destacado criterio económico en la interpretación del precepto (eficacia y sostenibilidad "aplicando criterios de rentabilidad económica") en la organización y racionalización de la Administración pública, en este caso, en la prestación de los servicios públicos.

Este criterio de interpretación económica, plantea dudas respecto a qué se aplica: si sólo a su sostenibilidad y eficacia, o también en su comparación con la eficiencia respecto a la contratación pública, oscuridad que sería urgente despejar, o mejor eliminar en este caso, por sus consecuencias, que se exponen a continuación. Asimismo, como se ha referido, la modificación en la versión del Proyecto respecto a la del Anteproyecto, que hace desaparecer la referencia a que se trata de una exigencia en la creación de medio propio o servicio técnico, aventura dificultades en su aplicación, esto es, si va referido a todas a las entidades del sector público, también de las existentes.

\section{CONSECUENCIAS Y ANÁLISIS DE LA REGULACIÓN QUE ESTABLECE EL ART. 85.2 DEL PROYECTO LRJSP}

Este precepto parece perjudicar y distorsiona la tradición y modelo del Estado social en Europa, con servicios públicos que prestan en principio las Administraciones, pues parece tener como presupuesto político el modelo de prestación de servicios en Estados Unidos a través de empresas a las que se les imponen cargas o criterios de calidad, y en consecuencia posiblemente tampoco respeta su regulación en nuestro texto constitucional y ordenamiento jurídico, como se expone a continuación.

Así, en primer término, parece distorsionar, como se ha referido, el principio de eficiencia y eficacia en la prestación de servicios públicos, y ello en atención a exclusivos o destacados criterios de rentabilidad económica (ubicados con cierta confusión voluntaria o al menos involuntariamente, por defecto de técnica legislativa), pues como critica la doctrina referida ${ }^{10}$, no deben enunciarse como objetivos los criterios que resultan como mediales o de medios para la consecución de los verdaderos objetivos (eficacia, en este caso en la prestación de servicios públicos).

Con este criterio de mera rentabilidad económica (¿como objetivo final o como simple medio para alcanzar la mejor prestación de servicios?) y la comparación de las entidades del sector público institucional, con la contratación del sector privado, se distorsiona asimismo el principio de servicio público a los ciudadanos de los arts. $3.1 \mathrm{f}$ ) y 4, LOFAGE, máxime teniendo en cuenta la referencia citada en el preámbulo, el servicio de las Administraciones "a los ciudadanos y las empresas"11.

De igual forma se debe poner de manifiesto cómo esta regulación del art. 86.2 del Proyecto, se aparta de la consecución de los principios rectores de la política social y económica encomendada a las Administraciones públicas en el art. 53.3 Const. y, en definitiva, del principio de objetividad en el funcionamiento de la Administración pública del artículo 103 Const. Téngase en cuenta al respecto, por ejemplo, la reciente STC 84/2015, que confirma $\left(\right.$ FD $\left.7 .^{\circ}\right)$ el carácter potestativo de la gestión indirecta de los servicios públicos, siempre que no suponga descono-

9 Sobre la discrecionalidad y racionalidad en la prestación de los servicios públicos, véase SANTAMARÍA PASTOR, obra citada, página 327; Luis ORTEGA, Lecciones y materiales para el estudio del Derecho administrativo, dirigido por MUÑOZ MACHADO, volumen II, 2009, página 49; PARADA VÁZQUEZ, Derecho administrativo, volumen II, 2014, páginas 337 y siguientes; David BLANQUER, Los contratos del sector público, 2013, capítulo 16, "Los contratos de gestión de servicios públicos", que refiere cómo la decisión no viene prejuzgada por el Derecho de la Unión Europea y no puede ser caprichosa con prejuicios de ideología política sino fundada en criterios objetivos de racionalidad económica y social.

10 VAQUER CABALLERÍA, loc cit.

11 Huelga la referencia expresa a las empresas. La lectura de la doctrina viene a explicar por qué en el ordenamiento jurídico se alude sólo al servicio a los ciudadanos y no a otros colectivos, o intereses. Piénsese por qué se alude sólo a las empresas y no por ejemplo a los consumidores o a los colegios profesionales, o a otro largo listado de intereses públicos y privados, a los que sirvan las Administraciones además de a los ciudadanos. En este sentido E. GARCÍA DE ENTERRARÍA y Tomás-Ramón FERNÁNDEZ RODRíGUEZ, Curso de Derecho administrativo, volumen II, 2011, página 17, se expone cómo el término ciudadano o administrado es una expresión que contrapone la dualidad Estado-ciudadano, público y privado, esto es, ciudadano como cualquier persona física o jurídica considerada desde su posición privada respecto a la Administración pública o sus agentes. Asimismo PAREJO ALFONSO, Lecciones de derecho administrativo, 2013, página 204, refiere las relaciones de este principio de servicio a los ciudadanos con el artículo 10.1 de la Constitución; y COSCULLUELA, en su Manual de Derecho administrativo, 2014, página 429, define ciudadano como "titular de derechos y libertades que la Constitución española les reconoce frente a todos los poderes públicos". 
cer la titularidad pública del servicio y la adecuada calidad ${ }^{12}$. Esta STC puede ser una referencia general, pero en ella se debe enmarcar y excluir, a mi juicio, esta regulación del art. 86.2 del Proyecto LRJSP, pues impide al menos la opción de las Administraciones en la prestación directa de los servicios públicos por entidades, en atención a criterios de calidad. Tal vez incluso, esta regulación en cierta medida puede poner en cierta discusión la titularidad pública de los servicios públicos, en cuanto pueda requerir que la prestación directa por entidad pública haya que justificarla frente a la prestación indirecta y en este sentido pueda resultar una excepción de facto, esto es, que la titularidad pública se sustituiría por la mera garantía en su prestación, pero no ya en la opción de su gestión consustancial a la titularidad.

De hecho esta redacción del art. 86.2 Proyecto LRJSP no atiende, a mi juicio, a la aplicación de criterios metodológicos de racionalización y racionalidad en la organización de las Administraciones públicas para la prestación de los servicios públicos, que se ha concretado tradicionalmente en la legislación de contratos, hoy del sector público, en la que, como se ha comentado, rige lógicamente el principio de prestación directa, al requerir que la indirecta sólo supondrá una mejor gestión económica y ahorro consecutivo en el caso de que no se puedan prestar los servicios necesarios por la propia Administración (o sus organismos o entidades, evidentemente), considerando que en principio al menos el coste de personal y estructural está ya amortizado, al abonarse en todo caso a los empleados públicos, por lo que la encomienda resultaría prima facie más rentable que la externalización del servicio mediante su concesión. Se pone en duda incluso la razonabilidad de la medida prevista, que sólo resulta racionalmente justificable si deviniera aplicable sólo, como se ha expuesto, como medida de "control de eficacia y supervisión continua", ya presente en el art. 85 Proyecto LRJSP. En este sentido cabe afirmar que lo que puede ser razonable e incluso necesario en un ámbito específico (la racionalización y control del gasto público), mediante una defectuosa regulación (art. 86.2 Proyecto LRJSP) o en su caso voluntaria extensión, puede resultar nefasta y contraria al ordenamiento jurídico.

La irracionalidad de la medida incluida en el art. 86.2 Proyecto LRJSP con el objetivo paradójico de racionalizar el sector público, resulta evidenciada asimismo tras su contraste con el legislador autonómico, en concreto con la Ley gallega 14/2013 de racionalización del sector público autonómico, cuyo artículo 8 impone la autoprovisión en la gestión de servicios públicos, de forma que, como se ha expuesto en el ámbito de la legislación estatal de con-

12 "La posible apertura a formas de gestión y responsabilidad privada se lleva a cabo preservando en todo caso la titularidad pública del servicio... La norma recurrida, de hecho, apoya la previsión en lo dispuesto en el ya mencionado artículo único de la Ley $15 / 1997$, de 25 de abril, sobre habilitación de nuevas formas de gestión del Sistema Nacional de Salud, que, entre otras posibilidades, dispone que la prestación y gestión de los servicios sanitarios podrá llevarse a cabo mediante acuerdos, convenios o contratos con personas o entidades públicas o privadas. Tal regulación, además, resulta concordante, en lo que ahora interesa, con la normativa sobre contratación pública (conforme al art. 275.1 del texto refundido de la Ley de contratos del sector público, "la Administración podrá gestionar indirectamente, mediante contrato, los servicios de su competencia, siempre que sean susceptibles de explotación por particulares. En ningún caso podrán prestarse por gestión indirecta los servicios que impliquen ejercicio de la autoridad inherente a los poderes públicos”). “... La definición de las prestaciones a las que tienen derecho los ciudadanos queda en manos, en todo caso, de los poderes públicos, no habiéndose producido un traslado de esta potestad a quienes asuman la gestión —y solo la gestión- del servicio público de la sanidad; la financiación se lleva a cabo asimismo mediante fondos públicos, sin que las singularidades a las que pueda dar lugar aquí la preservación del equilibrio financiero del adjudicatario alcancen tal grado de intensidad que hagan inconstitucional el modelo de gestión establecido; y, finalmente, el art. 62.1 in fine alude expresamente a la garantía de "los adecuados niveles de atención y derechos de los usuarios". No se aprecia, por tanto, que la previsión recurrida ponga en cuestión los rasgos estructurales de la institución Seguridad Social ni que se desnaturalice su esencia. “...c) Culminan este motivo impugnatorio los senadores promotores de este recurso de inconstitucionalidad sosteniendo que el sistema de gestión de la sanidad establecido en el precepto legal controvertido es contrario al principio de igualdad proclamado por el art. $14 \mathrm{CE}$, en la medida en que comporta desigualdades injustas entre los ciudadanos de una misma Comunidad, según pertenezcan a una zona sanitaria de gestión directa o según estén asignados a alguno de los seis hospitales relacionados en la norma, respecto a los que se parte del presupuesto de que en ellos regirá un sistema de gestión indirecta mediante concesión administrativa a empresas privadas y con un régimen de capitación, deduciendo a partir de esta premisa una posible dinámica respecto a las preferencias de estos hospitales por atender aquellos pacientes y procesos que les pueden ser más ventajosos económicamente, con consecuencias financieras derivadas. "Respecto a esta argumentación, de nuevo hay que insistir en que el art. 62 de la Ley $8 / 2012$ no predetermina ni la modalidad ni el contenido obligacional del contrato para la gestión del servicio público de asistencia sanitaria especializada en los seis hospitales que indica. Además, la fundamentación ofrecida por los recurrentes se sustenta en presunciones, conjeturas o deducciones propias sobre la eventual dinámica que puedan seguir las adjudicatarias de la gestión, pero no se construye sobre datos normativos que establezcan las desigualdades denunciadas. Como se ha reiterado, el tenor del precepto se limita a habilitar la posible adjudicación de contratos para la gestión de la asistencia sanitaria especializada. Sin embargo, por sí solo, no establece ninguna diferencia de trato en cuanto al contenido, alcance o calidad de la prestación sanitaria que hayan de recibir los ciudadanos asignados a esos seis hospitales. Por el contrario, la propia norma recurrida se encarga de precisar que en la contratación adjudicada se garantizarán "los adecuados niveles de calidad, atención y derechos de los usuarios", derechos entre los que se encuentra la garantía de accesibilidad de todos los usuarios del Sistema Nacional de Salud a las prestaciones sanitarias "en condiciones de igualdad efectiva" (art. 23 de la Ley 16/2003, de 28 de mayo, de cohesión y calidad del Sistema Nacional de Salud; y arts. 2 y 6 de la Ley 12/2001, de 21 de diciembre, de ordenación sanitaria de la Comunidad de Madrid).” 
tratos, la contratación sólo será posible cuando el servicio no pueda ser prestado por la Administración pública13, y ello porque evidentemente en la consecución del objetivo de eficiencia económica en la gestión del gasto público, la existencia de órganos u organizaciones administrativas capaces de prestar el servicio, resulta en principio más rentable que su contratación, teniendo en cuenta que puede suponer una artificial duplicación de gastos, al existir ya esos órganos u organizaciones administrativas que asumirán la actividad sin costes de personal adicional ningunos.

Finalmente, la eventual racionalidad y ponderación con el sector privado se determina sólo respecto a la prestación directa de servicios públicos por entidades distintas de la Administración (organismos autónomos, entidades públicas empresariales, entidades privadas de capital público), sin que se entienda bien si esa racionalidad debe ser sólo predicada respecto a los que es mera Administración institucional y material. En este sentido, la necesidad de ponderación en la gestión directa por la contratación de la prestación del servicio público, que eventualmente puede imponer este art. 86.2 Proyecto LRJSP, podría llevar a su vez a una interpretación o resultado tampoco perseguido por el legislador, y tal vez absurdo, pero que podría imponerse como salida a la concurrencia de la prestación directa por entidades públicas con el sector privado, como es que los servicios públicos se mantengan siempre bajo formas de gestión indiferenciada o por órgano especializado pero en el seno de la misma Administración ${ }^{14}$, esto es, por la propia Administración sin recurrir a la Administración institucional o instrumental y a la material por entidades privadas de capital público, para evitar así tener que competir con el sector privado a la hora de tener que plantear la opción de gestión directa o indirecta del servicio, es decir, preferir siempre la gestión directa mediante la propia Administración no institucional ( $v$. gr. puertos gestionados por una Dirección General del Ministerio de Fomento en lugar de por una Entidad), pues el art. 86. 2 Proyecto LRJSP no se refiere a esta Administración indiferenciada o especializada en la misma Administración. Esto dificultaría o limitaría de raíz el recurso a la Administración institucional y material por entidad privada de capital público, y de tenerse en consideración podría perjudicar la gestión de servicios públicos de complejidad técnica o con gran tráfico económico, en la medida en que se impidiera que fueran gestionadas por entidades públicas, que tendrían que "competir" con criterios exclusivamente económicos con el sector privado (adjudicación de servicios públicos mediante concesión de servicios públicos).

\section{REFLEXIÓN FINAL}

El inútil y en todo caso pernicioso derroche en el gasto público, es la auténtica medida a implantar por el legislador y a adoptar por las Administraciones mediante controles ciertos, más que su pretendida articulación con la gestión de servicios públicos, como se hace en este art. 86.2 Proyecto LRJSP, mediante la determinación del servicio a prestar y su calidad en atención a costes de mercado de una cualquier actividad, porque los servicios públicos no son cuantificables o evaluables necesariamente y en todo caso como meras actividades de mercado, no son sólo servicios o bienes, sino que evidentemente han sido juridificados en atención a una cualidad diferente, como

13 El artículo 8, titulado “Autoprovisión de bienes y de servicios dentro del propio sector público”, dispone:

“1. La Administración general de la Comunidad Autónoma y las entidades instrumentales del sector público, con la finalidad del uso eficiente de los recursos públicos existentes, realizarán las tareas de interés público que les corresponden con los medios personales, técnicos, materiales y de cualquier otro tipo de los que disponga el sector público autonómico.

"2. A los efectos indicados en el apartado anterior, cuando los medios de los que dispongan resulten insuficientes para el cumplimiento y realización de sus fines institucionales, acudirán con preferencia a la cooperación, colaboración y asistencia de otros órganos de la Administración general de la Comunidad Autónoma o de otras entidades del sector público autonómico que sí dispongan de los medios de los que precisan.

“3. A estos efectos se elaborarán, en los términos previstos en el artículo siguiente, catálogos de medios y prestaciones susceptibles de ser objeto de cooperación, colaboración y asistencia en el ámbito interno del sector público autonómico.

“4. Para los medios y prestaciones incluidos en el catálogo, sólo podrá acudirse a la contratación externa cuando la autoprovisión no resulte viable, por no poder ser cumplidamente satisfechas por otros órganos o entidades instrumentales del sector público las necesidades que se pretenden cubrir, mediante alguno de los procedimientos de colaboración indicados en la presente ley, por la insuficiencia, carencia o inadecuación de los medios de los que dispongan.

Estos aspectos deberán ser objeto de justificación en los expedientes de contratación en los términos previstos en el artículo 33 de la presente ley.

“5. En cualquier caso, si así está previsto en el catálogo, el órgano o entidad a la que habría correspondido la asunción de las tareas que serán objeto de contratación externa deberá supervisar y prestar asistencia en el proceso de contratación y en la ejecución de las prestaciones para velar por la coordinación y asegurarse de que no se generen duplicidades."

14 La "gestión indiferenciada" en la terminología doctrinal, entre otros supuestos de gestión directa, como expone, ESTEVE PARDO, Lecciones de derecho administrativo, 2014, página 439. Asimismo, ob. cit., páginas 440-441, refiere en concreto la calidad y el menor coste en la opción de gestión de servicios públicos, y con dos variantes a tener en cuenta en el modo de gestión directa, lo más adecuado en atención a la complejidad técnica y el tráfico económico, de forma que a mayor complejidad y tráfico económico se atenderá más a fórmulas organizativas con mayor autonomía, y a poca complejidad y bajo coste, se puede gestionar por la propia estructura ordinaria. 
servicios públicos, y por tanto su regulación se debe ponderar (art. 53.3 Const.) de forma mucho más cuidadosa que en el art. 86.2 Proyecto LRJSP. Por poner algún ejemplo simplificado de entre los muchos que todos conocemos: ¿se puede evaluar la limpieza viaria urbana con base en reducción de costes laborales, por ejemplo mediante el uso de máquinas de soplado para el barrido de calles, al margen de la misma contaminación sonora y del aire que llevan consigo? ¿O el abastecimiento de agua potable con el criterio de rentabilidad y el mínimo de calidad? La máxima calidad posible, sin duda incluyendo también, pero no sólo, criterios económicos, es el objetivo que guía la prestación de cualquier servicio público, así se deriva de nuestra tradición y se refleja en nuestro ordenamiento jurídico (art. 53.3 Const.), y eso es una gran diferencia respecto a la puesta a disposición de bienes y servicios en el mercado, y por ello la prestación indirecta de servicios, se ha articulado en nuestro ordenamiento como una técnica subsidiaria respecto a la directa (fuere o no por entidad diferenciada de la propia Administración, pues sigue siendo la propia Administración que sólo a efectos instrumentales se ha personificado), y su conjunción con la racionalización del gasto implica que sólo se gestione indirectamente en caso de insuficiencia de la organización pública.

Por todo ello, esta regulación del art. 86.2 Proyecto LRJSP no puede ampararse en el loable y necesario principio constitucional de racionalización del gasto público en la reciente España del despilfarro y corrupción, sino que se trata en realidad una mera reestructuración y minoración de la Administración y de los servicios públicos a los ciudadanos, que persigue un beneficiar y subvencionar al sector privado, contribuyendo así a mantener un sector privado fuertemente dependiente de las Administraciones públicas, lo que no parece aconsejable desde muchas perspectivas, políticas, económicas, pues esa dependencia puede perpetuar y acentuar la corrupción política en el seno de las Administraciones (que no de la de la Administración pública como institución), de la que tiene que huir y distanciarse claramente el legislador, y en todo caso, en lo que aquí concierne, esos fines político-económicos, así formulados como en el art. 86.2 Proyecto LRJSP, no tienen cabida en nuestro ordenamiento jurídico. 